\title{
Global mechanical tensioning for the management of residual stresses in welds
}

\author{
D.G. Richards ${ }^{\text {a }}$, P.B. Prangnell ${ }^{\text {a }}$, S.W. Williams ${ }^{\text {b }}$, P.J. Withers ${ }^{\text {a, }}$, \\ a School of Materials, Manchester University, Grosvenor Street, Manchester M1 7HS, UK \\ ${ }^{\mathrm{b}}$ Cranfield University, Welding Engineering Research Centre, Bedfordshire MK43 OAL, UK
}

Received 4 November 2007; received in revised form 14 December 2007; accepted 19 December 2007

\begin{abstract}
The general principles behind the global mechanical tensioning technique for controlling weld residual stresses are examined using a finite element model to follow their evolution throughout the welding process. While we focus specifically on friction stir welding, the tool is represented simply as a heat source. As a result, the findings have relevance to a wide range of welding processes. For aluminium alloy friction stir welds, the maximum longitudinal weld stresses have been reported to fall approximately linearly to zero under mechanical tensioning to a level around $40 \%$ of the yield stress. Under larger tensioning levels, the weld stress becomes increasingly compressive. This behaviour is explained in terms of the reduction in compressive plastic straining ahead, and an increase in tensile plastic straining behind, the heat source as the tensioning level is increased. Finally, it is shown that tensioning during welding is much more effective than post-weld tensioning.
\end{abstract}

(C) 2008 Elsevier B.V. All rights reserved.

Keywords: Mechanical Tensioning; Thermal tensioning; Friction stir welding; Low stress low distortion welding; FE modelling; Neutron diffraction; AA2024; AA7449

\section{Introduction}

Friction stir welding (FSW) is being used increasingly in a wide range of applications, particularly for joining aluminium alloys. The basic process has been described extensively elsewhere [1], but in essence involves a rotating tool consisting of a cylindrical shoulder and pin. The tool is plunged into the weld line until the shoulder is in contact with the plate surface. Once the material is sufficiently hot from frictional heating and plastic work, the tool traverses along the weld line and the hot plasticised material is extruded past the rotating pin, while constrained between the shoulder and backing bar, so as to form a joint behind the pin. Because FSW is a solid state welding method, it is particularly suited to joining high strength aluminium alloys that were previously considered unweldable using fusion techniques [1]. Although the process alleviates many of the metallurgical problems associated with fusion welding, such as liquation and

\footnotetext{
* Corresponding author.

E-mail addresses: david.g.richards@postgrad.manchester.ac.uk (D.G. Richards), philip.prangnell@manchester.ac.uk (P.B. Prangnell), s.williams@cranfield.ac.uk (S.W.Williams), philip.withers@manchester.ac.uk (P.J. Withers).
}

solidification cracking, friction stir welds can still suffer from significant levels of residual stress, which are often similar in magnitude to those seen in fusion welds [2-4]. In general terms, the residual stresses arise from plastic misfit strains introduced as a result of the steep gradients in temperature that are generated local to the heat source as the tool advances [5]. As tensile residual stresses in welded structures produced from high strength Al-alloys can have a negative impact on service life $[4,6,7]$, it is highly desirable to reduce their level as far as possible. One approach, that can be adopted to mitigate weld residual stresses, is to use weld tensioning methods to engineer the local stress state during welding by controlling the plastic misfit strains generated by the thermal field.

In welding the maximum tensile residual stresses are typically found on, or either side of, the weld line. These arise during cooling of the weld as a result of the compressive plastic misfit generated as the material expands and softens ahead of the heat source [5]. It has long been known that tensioning techniques can reduce residual stresses and the concomitant tendency for distortion (e.g. [8]). In practice, a large number of techniques have been proposed for controlling residual stresses in welding, including both thermal and mechanical tensioning methods. One of the earliest reported applications was by Greene and Holzbaur 
[9], who in 1946 used superimposed temperature gradients to achieve reduced residual stresses in longitudinal butt welds in ship hull structures. Local induction heating has also been investigated for residual stress improvement [10]. Michaleris and Sun [11] and Dull et al. [12] have applied thermal tensioning to reduce buckling distortion, whilst Dong et al. [13] developed an in-process thermal-stretching technique for effectively mitigating residual stresses and distortion on repair welding of aluminium panels. In addition, Barber et al. [14], van der Aa et al. [15] and Williams and co-workers [16], have applied local cooling, with either solid or liquid $\mathrm{CO}_{2}$ trailing the heat source, as a means of creating dynamically controlled low residual stress and distortion free welds. Several mechanical tensioning systems have also been proposed. Yang et al. $[17,18]$ have mechanically compressed the weld on cooling using a pair of rollers on both sides of the weld line, reducing both residual stress and buckling distortion. Finally, preliminary work by Williams et al. [8] has shown that the application of global, or far field, mechanical tensioning externally during the welding process can greatly reduce the tensile residual stresses in FSWs. In global mechanical tensioning a load is applied uniformly along opposite ends of the plates prior to clamping the parts for welding (see Fig. 1), so that a uniform tensile stress is maintained in the two butted plates parallel to the weld line. The clamping and tensioning loads are then released after the friction stir welding tool has traversed along the join line forming a weld. Perhaps counter-intuitively, Williams et al. found that high levels of mechanical tensioning parallel to the welding direction can actually reverse the state of stress, so that compressive longitudinal residual stresses are found in the weld region [8].

While a plethora of techniques for influencing the generation of plastic misfit strains and the resultant residual stresses during

(a)

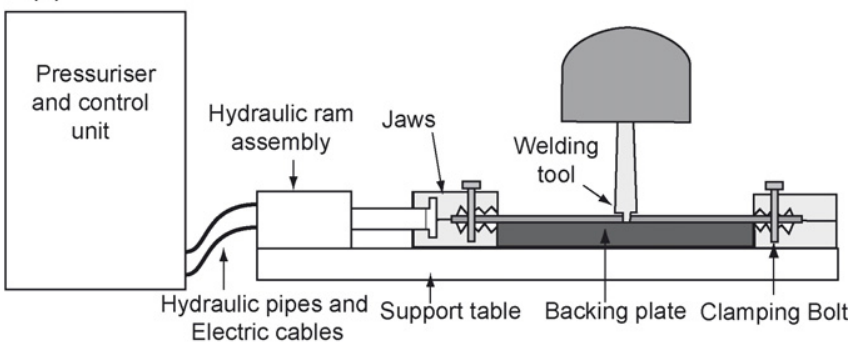

(b)

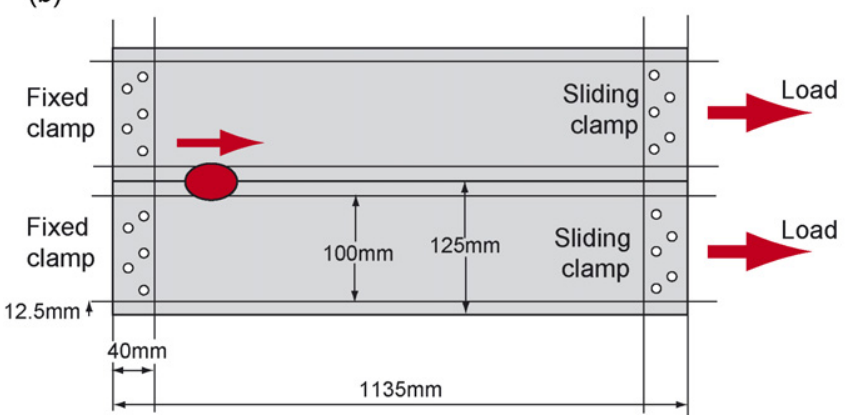

Fig. 1. Schematic diagrams showing (a) the global mechanical tensioning process and (b) the plate geometry for the 2024 plates. welding have emerged, at present very little work has been carried out into quantifying the effectiveness of these methods, or establishing their basic principles. This is in part because, to date, little modelling work has been carried out to study the underlying interactions between the externally imposed thermal or mechanical loads and the transient welding stresses. This paper aims to help fill this gap and thereby clarify the mechanism of mechanical tensioning. To this end we have focused on the mechanical tensioning of aluminium alloy friction stir welds. A simplified finite element model of the process has been developed and validated using experimental residual stress data available in the literature measured by X-ray synchrotron diffraction [8,19-21], for mechanically tensioned AA7449 and AA2024 FSW's. While modelling work has been carried out on the basic FSW process previously (e.g. [22-30]), few studies have focused on residual stress prediction $[26,29,30]$. The study by Preston et al. [30] did look at thermal tensioning, but none have looked in detail at the effect of mechanical tensioning on FSWs. Although this paper examines friction stir welding, because the development of residual stresses have been taken to be governed solely by the heat input, the general conclusions regarding the mechanisms of stress relief by mechanical tensioning are applicable to other welding processes.

\section{Methodology}

\subsection{Global mechanical tensioning experiments}

The examination of the mechanical tensioning method is based on friction stir welding trials undertaken by BAE Systems and Airbus UK and associated residual stress measurements described in detail elsewhere [8,19-21]. In essence, a hydraulic tensioning rig was used to apply a tensioning load uniformly along the ends of pairs of plates parallel to the weld line during welding. The plates were drilled at each end to allow rigid clamping in the tensioning rig, as shown in Fig. 1. Two types of plate were butt welded; $1135 \mathrm{~mm} \times 125 \mathrm{~mm} \times 3 \mathrm{~mm}$ panels of 2024 alloy in the T3 condition, and $1000 \mathrm{~mm} \times 250 \mathrm{~mm} \times 12 \mathrm{~mm}$ plates of 7449 alloy in the W51 condition. The tensioning stress levels were defined in terms of the percentage of the room temperature proof stress of the material, being up to $85 \%$ for the AA2024-T3 welds $\left(\sigma_{0.2}=345 \mathrm{MPa}\right)$ and $30 \%\left(\sigma_{0.2}=580 \mathrm{MPa}\right)$ for the stronger thicker AA7449-W51 plate. Except for the tensioning level, all the other welding conditions were maintained constant and are summarised in Table 1. The tool geometries are given in Table 2.

\subsection{FE modelling}

In order to elucidate the role of mechanical tensioning, finite element modelling has been used to study the evolution of the stress state through the process. The extensive material flow that occurs in friction stir welding means that it is not practical to develop a fully coupled thermo-plastic model that will run in a feasible time scale for typical weld geometries. Furthermore, previous work suggests that the residual stresses are primarily a function of the thermal excursion, and that the mechanical 
Table 1

Welding conditions and materials used in the tensioning trials, reported in the literature, and equivalent calibrated heat inputs used for the FE model

\begin{tabular}{|c|c|c|c|c|c|c|c|c|c|}
\hline Data set & Material & $\begin{array}{l}\text { Plate geometry } \\
\mathrm{L}, \mathrm{W}, \mathrm{D},(\mathrm{mm})\end{array}$ & $\begin{array}{l}\text { Rot'n speed } \\
\text { (rpm) }\end{array}$ & $\begin{array}{l}\text { Traverse speed } \\
(\mathrm{mm} / \mathrm{min})\end{array}$ & $\begin{array}{l}\text { Shoulder } \\
\text { power }(\mathrm{W})\end{array}$ & $\begin{array}{l}\text { Pin power } \\
\text { (W) }\end{array}$ & $\begin{array}{l}\text { Total power } \\
\text { (W) }\end{array}$ & $\begin{array}{l}\text { Peak temperature } \\
\left({ }^{\circ} \mathrm{C}\right)\end{array}$ & Ref. \\
\hline I & AA2024-T6 & $350 \times 250 \times 3$ & 770 & 195 & 862 & 96 & 958 & 487 & \\
\hline II & AA2024-T3 & $1135 \times 250 \times 3$ & 350 & 195 & 670 & $230^{\mathrm{a}}$ & $900^{\mathrm{a}}$ & $468^{a}$ & {$[19,20]$} \\
\hline III & AA7449-W51 & $1000 \times 250 \times 12$ & 225 & 250 & 1815 & 3033 & 4848 & 485 & {$[21]$} \\
\hline
\end{tabular}

${ }^{a}$ Estimated on the basis of the Colegrove CFD model [28] only.

Table 2

Tool geometries used in the welding trials reported in the literature for AA 2024 and AA7449 used to validate the FE tensioning model

\begin{tabular}{|c|c|c|c|c|c|}
\hline Data set & Material & Shoulder diameter $(\mathrm{mm})$ & Pin diameter (mm) & Pin length (mm) & Ref. \\
\hline I & AA2024-T6 & 16 & 4 & 2.8 & \\
\hline II & AA2024-T3 & 16 & 5 & 2.8 & {$[19,20]$} \\
\hline III & AA7449-W51 & 30 & 17 & 11 & [21] \\
\hline
\end{tabular}

deformation of the tool has relatively little effect besides that relating to the heat it generates $[2,23,26,31,32]$. The approach adopted was, therefore, to develop and validate a simplified model treating the tool solely as a heat source. The material flow and mechanical effects of the tool were thus not included. This simplification is computationally very efficient and has previously been found to give good results $[2,26]$; it also allowed a time-efficient investigation of the effects of important variables; such as tensioning level, heat input, and other boundary conditions. The FE model, implemented in ABAQUS, comprised two sequentially linked 3D simulations-a calibrated heat transfer model to imitate the weld thermal cycle, followed by a mechanical model in which the thermal cycle and boundary constraints are applied.

\subsection{Heat input}

In the heat transfer model the tool was represented by a circular surface source for the shoulder and a cylindrical volume source for the pin using the actual tool dimensions. In this simplified tool representation no surface features (flutes or threads) were included. This composite heat source was then traversed along the virtual weld line. To aid simplicity, based on the work of Chao et al. [23,32], the distribution of the heat flux under the tool shoulder, $q_{\mathrm{s}}$, was assumed to vary linearly with angular velocity, given by

$q_{\mathrm{s}}(r)=\frac{3}{(2 \pi)} \frac{Q_{\mathrm{s}} r}{\left(R_{\mathrm{S}}^{3}-R_{\mathrm{p}}^{3}\right)} \quad$ for $\quad R_{\mathrm{p}} \leq r \leq R_{\mathrm{S}}$

$R_{\mathrm{S}}$ and $R_{\mathrm{p}}$ are the dimensions of the shoulder and pin and $r$ is the radial distance. The heat input from the pin was assumed to be uniform along the length of the pin.

To obtain the net tool shoulder and pin power input terms two strategies were followed. The simplest approach was to fit the power transferred by the pin, $\left(Q_{\mathrm{p}}\right)$, and shoulder, $\left(Q_{\mathrm{s}}\right)$, by matching the FE simulations to thermal infrared imaging data and thermocouples placed in the work-piece of actual welding experiments (see Fig. 2). A more satisfying approach was to use a model to predict the heat input and a computational fluid dynamics (CFD) model developed by Colegrove et al. (described in detail in [28,33-36]) was used for this purpose. The model includes the strain rate sensitivity of the material and the limiting effects of liquation at the tool boundary layer at high temperatures and can be used to predict the power transferred by the pin and shoulder, as well as the corresponding weld temperatures, as a function of the welding parameters (Fig. 2(b)). While used here for making realistic estimates of the heat input, as a function of the welding conditions, the model still requires fitting of the effective shoulder contact area and calibration for different materials, and so must also be compared to measured results. A
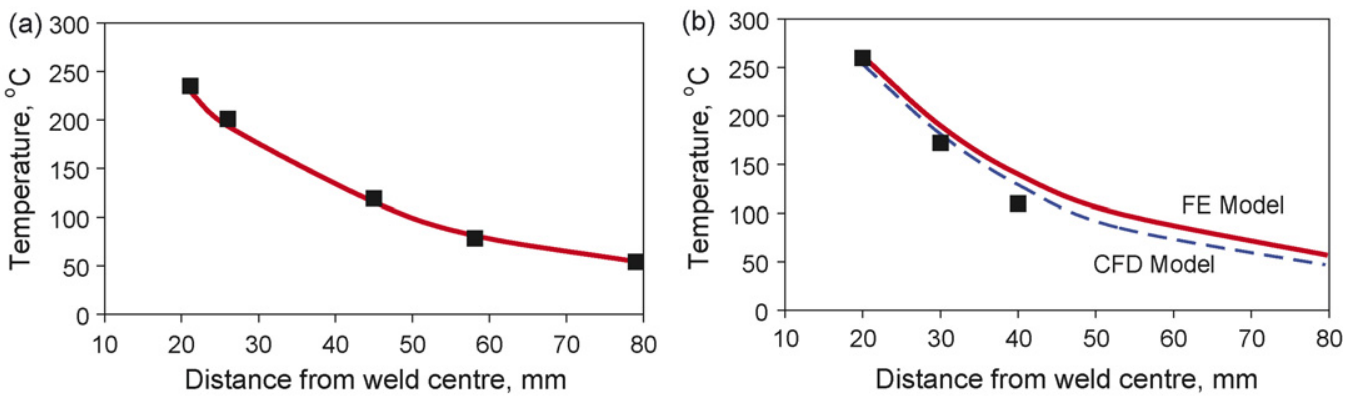

Fig. 2. Comparison of experimentally measured (squares) peak temperature profiles, recorded transverse to the welding direction, with the corresponding fit (lines) achieved using the FE model, (a) with data from infra-red thermal imaging for a weld in the AA2024 plate (welding parameters: $770 \mathrm{rpm}, 195 \mathrm{~mm} / \mathrm{min}$ ), and (b) using thermocouple and the Colegrove CFD model predictions for a weld in AA7449 $(225 \mathrm{rpm}, 250 \mathrm{~mm} / \mathrm{min})$. 
longer term aim is to couple these models to give a more realistic representation of the power distribution over the tool surfaces in the FE residual stress model. However, experiments conducted to study the influence of varying the power distribution function used for the tool surfaces has found negligible effect on the residual stress distribution, which is not greatly affected by temperature gradients very close to the tool interface.

The powers and peak weld temperatures were obtained using the Colegrove CFD model as an initial guide and fitting FE simulations to infra red camera and thermocouple data reported for the AA2024 and AA7449 welds. These are summarised in Table 1. It should be noted that no experimental thermal measurements were available for the set of tensioned weld data in the AA2024-T3 plate. In this case the power values given were estimated by the Colegrove CFD model alone. The tool geometries are summarised in Table 2. Thermocouple data [23,31,37] in thin plate materials suggest that $80-90 \%$ of the heat flux in friction stir welding is typically provided by the tool shoulder. However, for thicker material, CFD simulations showed that as the pin interface area grows, so does its power contribution. As a result, a 90:10\% ratio was utilised for the smallest tool geometry used for the AA2024-T6 thin plate material (Data Set I-see Table 1), increasing to a 75:25\% ratio for the slightly larger diameter pin used with the AA2024-T3 plate at the slower rotation speed (Data Set II). Finally, a 40:60\% ratio in favour of the pin was found to be appropriate for the $12 \mathrm{~mm}$ thick AA7449-W51 plate (Data Set III).

\subsection{Model geometry and boundary conditions}

The heat transfer model was based on a single partitioned plate having the same dimensions as the actual tensioned plates, the partition line being along the weld line. A graded mesh was used with DC3D8 brick elements at the weld line of $1 \mathrm{~mm} \times 1 \mathrm{~mm} \times 1 \mathrm{~mm}$ for the $3 \mathrm{~mm}$ plate and $1 \mathrm{~mm} \times 1 \mathrm{~mm} \times 3 \mathrm{~mm}$ for the $12 \mathrm{~mm}$ thick plate, increasing to $25 \mathrm{~mm} \times 25 \mathrm{~mm} \times 3 \mathrm{~mm}$ at the edge of both plate geometries, using DC3D6 wedge elements in this area. These elements were substituted by their direct equivalents in the mechanical model. The plate was pinned vertically along its length at $40 \mathrm{~mm}$ from the weld line to simulate clamping and the tension force was applied parallel to the welding direction along one end, with the other end fixed in the welding direction, prior to clamping. The heat transfer model was split into welding and cooling steps. The tool was 'plunged' by applying the heat source with a $5 \mathrm{~s}$ dwell time at the beginning of the weld located $50 \mathrm{~mm}$ in from the start of the plates. Heat loss to the base-plate and retaining clamps was simulated using artificial surface convection coefficients to simulate conduction. This method allowed the jigging parts to be omitted from the model, saving on simulation times. The 3D stress model was split into tensioning, clamping, welding, cooling and untensioning and clamp removal steps. Throughout this paper the stress components $\sigma_{11}, \sigma_{22}$, and $\sigma_{33}$ are taken to be aligned parallel to the welding direction, transverse to the weld line and normal to the plate, respectively.

\subsection{Material representation}

To accurately predict the evolution of residual stress it is important to capture the response of the material's yield stress to temperature, as well as the extent to which it is softened by microstructural changes during welding. For heat treatable Alalloys softening, caused by the dissolution and coarsening of precipitates during the high temperature excursion, is considerable and if not taken into account leads to over estimation of the residual stresses [29]. A kinetically dependent softening model was therefore used to allow interpolation of the materials yield stress, as a function of the thermal cycle experienced by each node, between two extremes; namely, the behaviour of the plate in its initial heat treated condition and in a fully softened overaged condition.

The measured upper and lower bound curves for yield stress as a function of temperature (supplied by Harrison [38]), were derived from hot tensile tests from the parent material and a fully overaged microstructure, obtained by machining samples from the HAZ minimum hardness region. The hardness level in the latter region had 'bottomed out' corresponding to a fully softened condition. A kinetic model was then used to smooth the transition between the two states by calculating the fraction of softening that occurred during the weld thermal cycle. This model was adapted from recent work by Sullivan and Robson [39] on weld zone hardness prediction and is based on relating the integrated weld thermal cycle to an effective aging time using a master curve empirically determined from isothermal treatments.

A more detailed description of this approach is described elsewhere $[39,40]$. In brief; the fraction of softening, $X_{\mathrm{p}}$, is defined as

$X_{\mathrm{p}}=\frac{\sigma_{\mathrm{y}}-\sigma_{\min }}{\sigma_{\max }-\sigma_{\min }}=1-\left(\frac{t_{(\mathrm{T})}}{t_{(\mathrm{T})}^{*}}\right)^{1 / 2}$

$\sigma_{\mathrm{y}}, \sigma_{\min }, \sigma_{\max }$, refer to the yield stress, the minimum yield stress in a fully softened state, and the maximum initial yield stress, respectively $t$ is the time and $t^{*}$ the time for complete softening at the same temperature $T . t^{*}$ at any temperature is related to the time for complete softening at a reference temperature, $T_{\mathrm{r}}$ by

$t_{(\mathrm{T})}^{*}=t_{\mathrm{r}} \exp \left(\frac{Q}{R}\left(\frac{1}{T}-\frac{1}{T_{\mathrm{r}}}\right)\right)$

where $Q$ is a fitted activation energy. A cumulative effective time fraction, in a time increment $\delta t$, at an instantaneous temperature, $T$, for each iteration $(i)$, is then maintained by

$\frac{t_{i}}{t_{\mathrm{eff}}^{*}}=\frac{t_{(i-1)}}{t_{\mathrm{eff}}^{*}}+\frac{\partial t}{t_{\left(\mathrm{T}_{i}\right)}^{*}}$.

For each time increment the fraction of softening is then updated from a master plot of $\ln \left(1-X_{\mathrm{p}}\right)$ versus $\ln \left(t / t^{*}\right)$ [39]. This is implemented in ABAQUS though a subroutine that tracks the fraction of softening ( $X_{\mathrm{p}}=0$ to 1$)$ accumulated at each node as it undergoes its individual local thermal cycle. The actual value of yield stress at the instantaneous temperature of every node is then obtained for each time increment by a weighted interpola- 

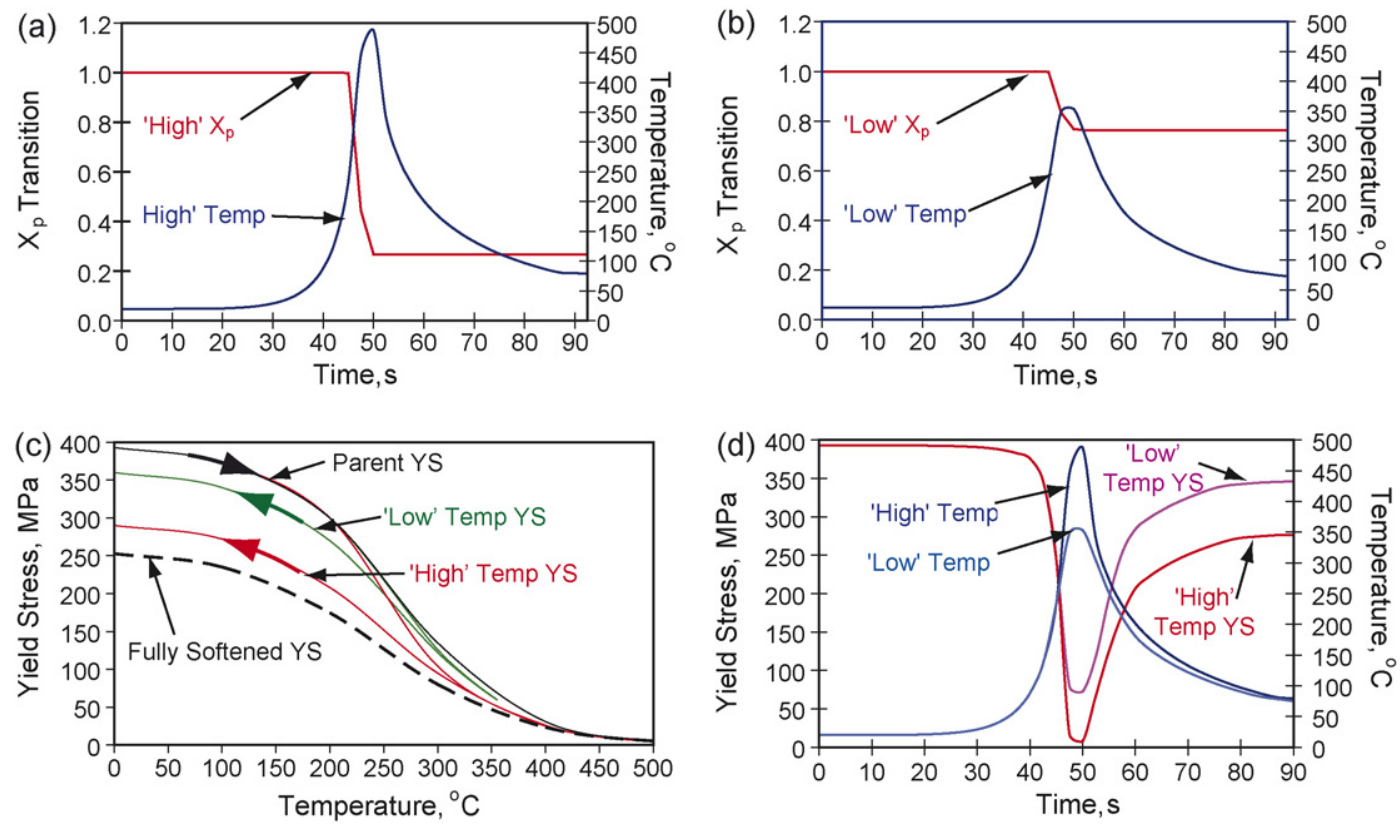

Fig. 3. Illustration of the approach used to simulate the variation of yield stress, as a function of thermal history, for local weld thermal cycles in a AA2024-T6 weld. In (a) and (b), the softening parameter $X_{\mathrm{p}}$ is plotted for 'high' $\left(490^{\circ} \mathrm{C}\right.$ peak; at the weld line) and 'low' $\left(350^{\circ} \mathrm{C}\right.$ peak; $8.5 \mathrm{~mm}$ from the weld line) temperature excursions, in (c), the flow stress is shown for heating to 'high' and 'low' temperatures and cooling, relative to the upper and lower bound curves, and in (d) the yield stress responses as a function of time for the 'high' and 'low' thermal excursions is given.

tion between the upper and lower bound measured yield stress curves in proportion to $X_{\mathrm{p}}$. It should be noted that although temperatures are expressed in degrees Kelvin in the equations; for convenience the temperatures in the figures are expressed in degrees Celsius.

This approach is illustrated in Fig. 3 for a 'high' temperature $\left(490{ }^{\circ} \mathrm{C}\right.$ peak) thermal excursion, corresponding to a node at the weld line and a 'low' temperature $\left(350^{\circ} \mathrm{C}\right.$ peak) thermal excursion corresponding to a node $8.5 \mathrm{~mm}$ from the weld line. In Fig. 3(a) the accumulated softening parameter can be seen to respond very rapidly as the maximum temperature is approached. In Fig. 3(c) the interpolated material flow stress path is shown as a function of temperature. On heating it follows the parent curve until close to the peak temperature, whereupon softening starts to occur, and on cooling it then tracks a path between the parent and fully softened conditions, scaled by the accumulated softening fraction, $X_{\mathrm{p}}$. In
Fig. 3(d) it can be seen that on completion of the weld cycle a node has a permanently lowered yield stress, by an amount dependent on the degree of thermal exposure during the weld cycle.

It should be noted here that the principles used in the softening model are only strictly valid for a material that does not undergo any further precipitation hardening during heat treatment. However, the paucity of experimental residual stress data in the literature on instrumented welds made it necessary to apply the model to the 2024-T3 and 7449-W51 materials, which are in a solution treated condition, so as to smooth the transition between parent properties and the microstructurally modified weld material. Nevertheless, a reasonable fit was still obtained, for both the 2024 T3 and 7449-W51 materials (see Figs. 4 and 5). Although this subtle difference is not critical to the current investigation of the principles of the mechanical tensioning method, subsequent simulations to investigate the effect of welding con-
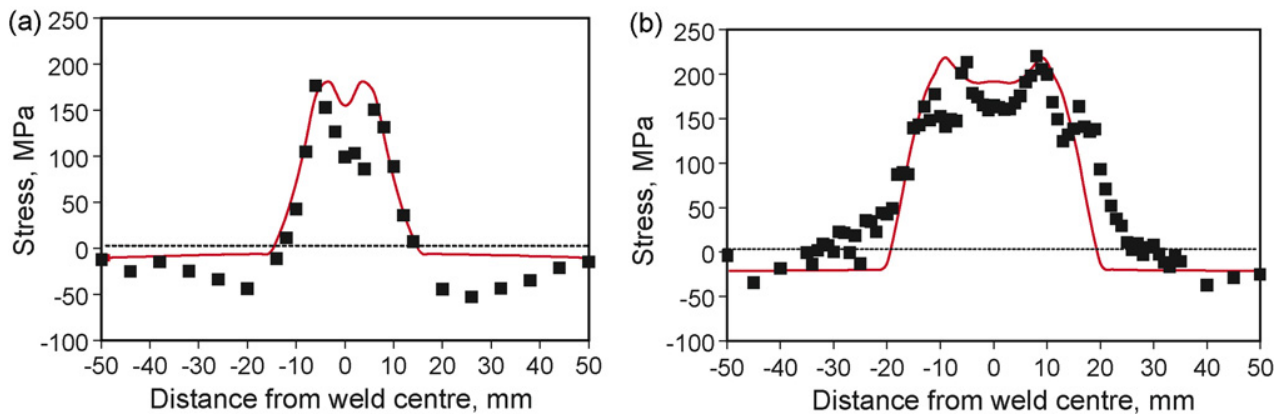

Fig. 4. Measured (squares) and predicted longitudinal stress profiles from the mid depth across the centre of welded plates as a function of distance transverse to the weld line, in (a), for an untensioned AA2024-T3 weld [19,20], and in (b) a AA7449-W51 weld tensioned to $10 \% \sigma_{0.2}$ [21], both measured by energy dispersive synchrotron X-ray diffraction with the advancing side on the RHS. The welds were produced under the standard welding conditions given in Table 1. 

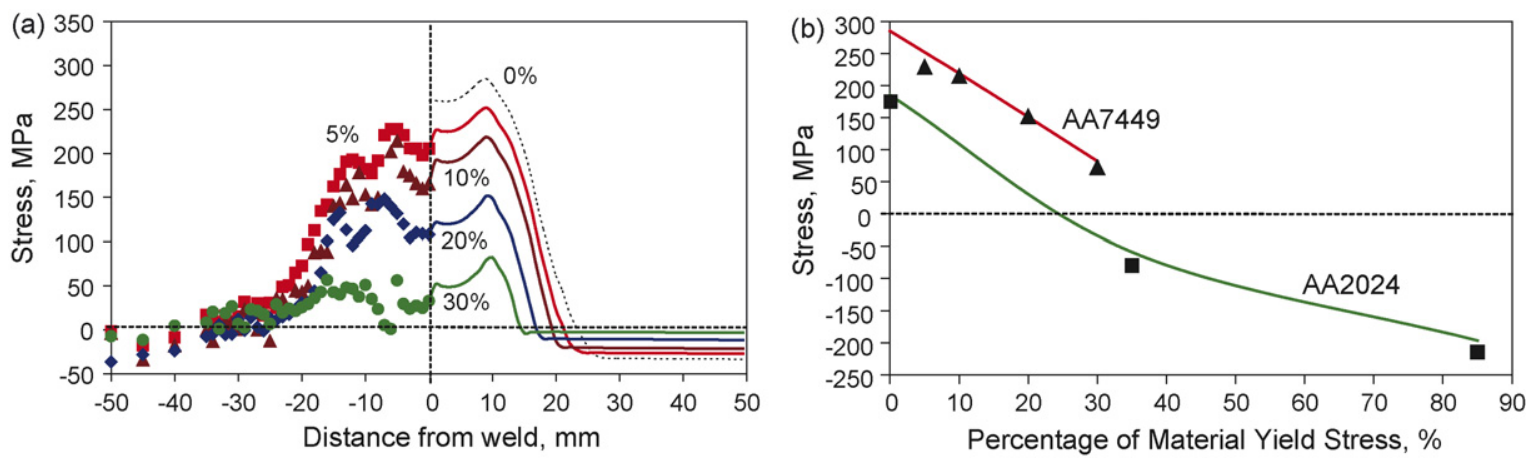

Fig. 5. (a) Comparison of the measured (points) [21] (LHS) and predicted (RHS) longitudinal stress profiles for AA7449-W51 welded plates as a function of different tensioning levels $(0,5,10,20,30 \%)$. The dotted profile represents the predicted untensioned $(0 \%)$ case for which there were no measured results. In (b) all the available data is summarised as a function of tensioning level by plotting the peak longitudinal stresses measured for AA7449 (triangles) and AA2024 (squares) compared with the model predictions (lines). Measured data provided by Steuwer et al. [19], Williams et al. [20] and Altenkirch et al. [21].

ditions and other tensioning variables were carried out using the 2024 material in the T6 condition.

\section{Results and discussion}

\subsection{Model validation}

The FE model was validated against residual stress data available in the literature obtained by synchrotron diffraction for AA2024-T3 [19,20], and AA7449-W51 [21] friction stir welds. Examples of comparisons between the modelling predictions and diffraction measurements are shown in Figs. 4 and 5, for welds produced using the conditions given in Table 1 . In all cases the diffraction data were corrected for instrument and solute related unstrained lattice parameter $\left(d_{0}\right)$ effects [41]. The use of multiple-peak fitting ensured that the effect of type II stresses were minimised and elastic constants typical of the bulk could be used.

Published data for untensioned AA2024-T3 (Data Set II) and AA7449-W51 (Data Set III) welds tensioned to $10 \%$ are shown in Fig. 4. In both cases a characteristic ' $M$ ' shaped stress profile is observed, as has been reported in other studies $[2,42]$, the origin of which will be discussed below. For the AA2024 plate, (Fig. 4(a)), it can be seen that the model corresponds well to the measured profile. The measured stresses are slightly asymmetric about the weld centreline, with higher stresses on the advancing side of the weld. This effect has also been observed by Peel et al. [2] and is probably due to an asymmetric temperature distribution arising from the direction of rotation of the tool. For the thicker 10\% tensioned AA7449 weld in Fig. 4(b), a close match is also seen between the predictions of the weld model and the synchrotron X-ray data [21], certainly well within the total error arising from counting statistics $( \pm 5 \mathrm{MPa})$.

The variations in measured and predicted weld stresses are plotted as a function of tensioning level in Fig. 5. Very close agreement is observed in Fig. 5(a) between the form of the measured (LHS) and predicted (RHS) longitudinal stress profiles for AA7449-W51. In Fig. 5(b) the peak longitudinal residual stresses reported for both AA2024-T3 and AA7449-W51 welds are plotted as a function of tensioning level and conform well to the predicted trends. Due to a lack of thermal measurements being available for these welding conditions, the predictions for the AA2024-T3 samples (Data Set II) were obtained by estimating the heat input by means of the Colegrove CFD model. Although this meant there was no means of validating the weld power, the predicted trend is in excellent agreement with the reported results. This gives further confidence in the trends predicted by the model. Both the measured and model predictions in Fig. 5(b) show an approximately linear variation in peak residual stresses, with the peak stress falling to zero at tensioning loads of between 30 and $45 \%$ of the room temperature proof stress of the parent material and becoming compressive thereafter. Indeed, at a tensioning level of $85 \%$ of the yield stress, the maximum longitudinal stresses in the AA2024-T3 plate have completely reversed reaching $-210 \mathrm{MPa}$.

In summary, the published results suggest that global mechanical tensioning is extremely effective in mitigating the large tensile longitudinal residual stresses developed during welding. The simplified modelling approach adopted here appears to fit the data well. This agreement supports its use in exploring the basic principles underlying the tensioning method and establishing the global trends that operate in mechanical tensioning.

\section{Principles of mechanical tensioning}

In the following discussion, the validated model for the $3 \mathrm{~mm}$ 2024-T6 plate is used to examine the evolution of temperature and stress during welding as a function of mechanical tensioning level. From the previous section it is clear that tensioning has a significant influence on the final residual stress state after welding. To give an initial overview of the effect of the heat source without tensioning, Fig. 6 shows 2D maps of the thermal field and the longitudinal and transverse stress fields predicted by the model. Of particular note in Fig. 6(b) and (c) is the bowwave of compressive stress ahead of the tool generated by the expansion of the hot material, and the increasing longitudinal tensile stresses forming behind the heat source in the vicinity of the weld line, as the consolidated weld material cools in the wake of the heat source. To gain a better picture of how mechan- 

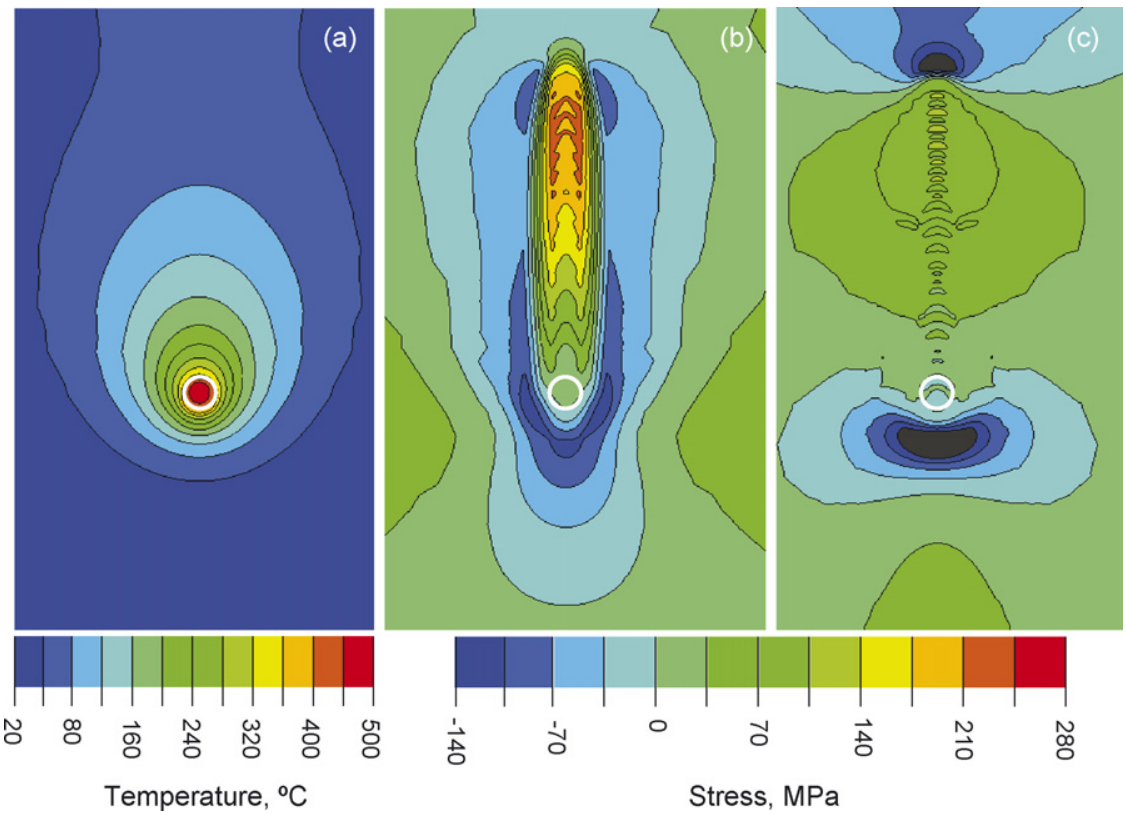

Fig. 6. In (a) thermal field predicted by the heat transfer model for AA2024-T6 plates $50 \mathrm{~s}$ into an un-tensioned weld using a heat input of $958 \mathrm{~W}$ ( $770 \mathrm{rpm}$, $195 \mathrm{~mm} / \mathrm{min}$ ), in (b) the corresponding predicted longitudinal stresses at the same instant, and in (c) the predicted transverse stresses. The position of the weld tool shoulder (moving downwards) is marked in each case by a white circle. The weld start location is also evident near the top of the figure. The view is $150 \mathrm{~mm}$ wide in each case.

ical tensioning affects the development of residual stress during welding, it is helpful to look more deeply into the evolution of the stresses with time as the tool traverses the plate relative to a fixed point within the material. To this end, the predicted lateral variation in longitudinal $\left(\sigma_{11}\right)$ mid-thickness stress profiles are shown in Fig. 7 for simulations of AA2024-T6 plates subjected to tensioning levels of $0 \%, 35 \%$ and $70 \%$ as the heat source travels past.

\subsection{Behaviour of an untensioned weld}

The general development of residual stresses in conventional untensioned welds has been widely described in the literature for fusion welding [29]. Fig. 7(b) demonstrates that ahead of the tool the compressive stress caused by the expanding hot material impinges on the compressive yield stress locus, causing plastic straining. Just behind the tool longitudinal tensile stresses begin to generate as the weld material cools. Initially stress development near to the weld line is limited by the low tensile yield stress (Fig. 7(d)). This local tensile plastic straining at the weld-line results in the initial formation of the ' $\mathrm{M}$ ' shaped residual stress profiles typically observed in the welded plate (Fig. 7(e)), as the hot region plastically deformed in compression, to a greater width, ahead of the tool becomes tensilely stressed as it cools behind the tool. As the tool travels forwards and the temperature falls, the tensile stress level builds up at a rate slower than that at which the yield stress rises so that a point is reached very soon after the tool has passed when no further yielding occurs (see Fig. 8(a)) and the increasing misfit is then accommodated elastically. As the tensile stresses develop near the weld-line these are balanced by a compressive stress towards the edges of the plate. On complete cooling (Fig. 7(e)) and removal of the clamping, a small amount of redistribution occurs. The final residual stress levels retained in the plate are, therefore, very sensitive to the interaction of the flow stress and the kinetically dependent softening behaviour of the material, in relation to the developing thermal field.

It is clear from Figs. 6(c) and 8(a) that the transverse stresses, which are often ignored in a simple analysis, are also very important. Indeed ahead of the tool the transverse compressive stresses contribute to plastic yielding. Behind the tool the transverse stresses are much less significant on the weld line. As one would expect, the normal component of stress, $\sigma_{33}$, is very small in the thin plate (the confining pressure of the tool shoulder has been neglected in the model). It is also clear from Fig. 9(b) that most of the compressive longitudinal plastic misfit, responsible for the final residual stresses, is introduced directly under the tool and that once the tool has passed completely no more plastic strain is generated so that the final residual stress state is simply a consequence of this misfit once the plate has completely cooled.

In the simple model adopted here the true nature of the tool and material flow is not represented, so predictions in the immediate vicinity of the heat source should be treated with caution. For example, directly under the tool the material will experience a compressive normal stress due to the down force and there will be an imposed torque. Of course for friction stir welding, there is also considerable plasticity specifically due to the motion of the tool. Microstructural evidence suggests that this material flow only affects the region well within the tool shoulder $(8 \mathrm{~mm}$ radius in this case for 2024). It can be seen in Fig. 8 that within this region the stress is essentially zero and misfits are accommodated completely plastically so that it is not sensitive to further plastic flow. Furthermore the compressive field ahead of the 

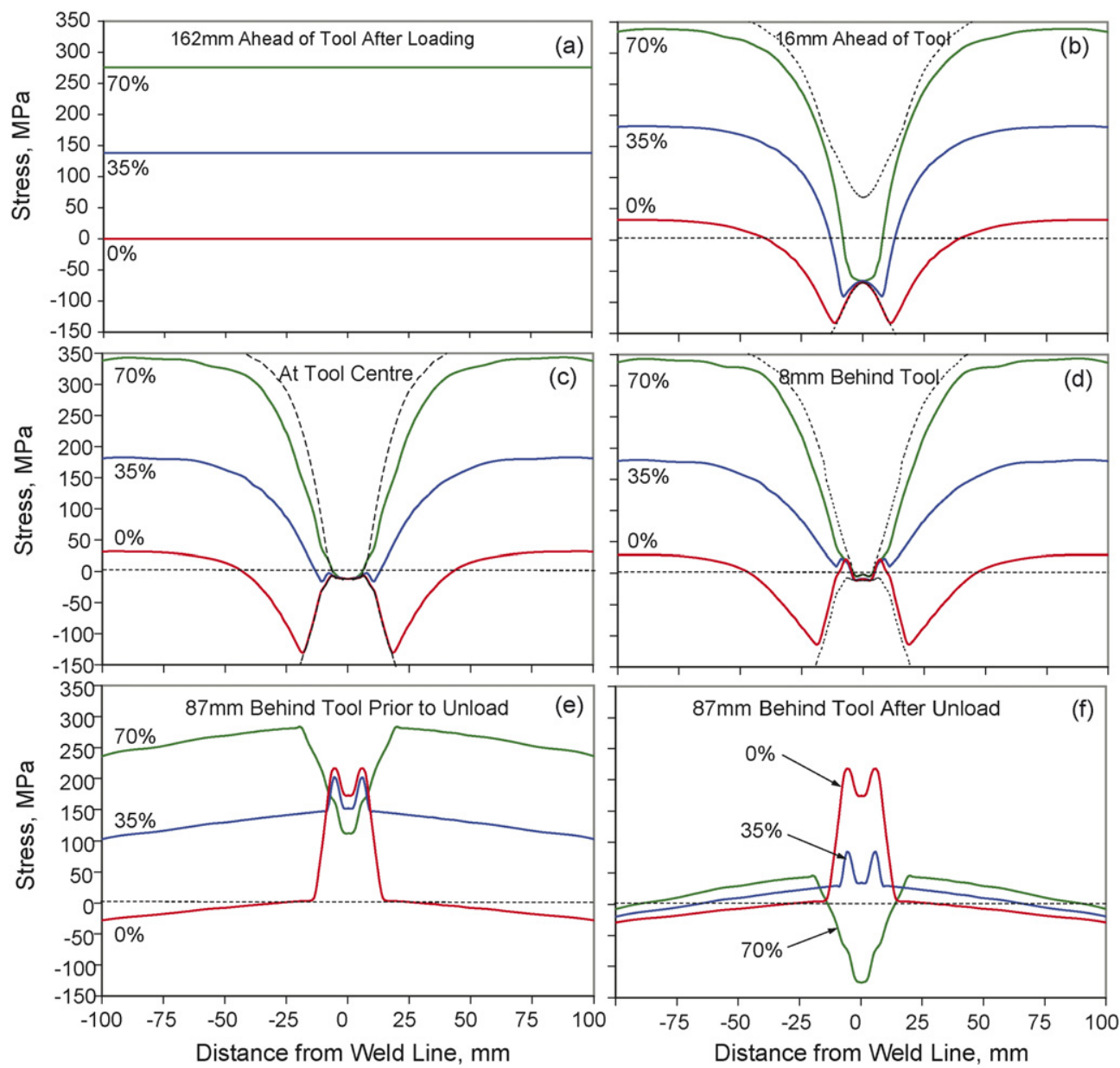

Fig. 7. Predicted longitudinal residual stress profiles and the tensile and compressive yield loci (dashed lines) across the mid-plane of the weld at different distances from the tool; (a) well ahead of the tool's thermal field, (b) as the heat source approaches and compressive stresses form, (c) directly through the tool centre, showing the resultant reduction in thermal strain by compressive yielding, in (d) at $8 \mathrm{~mm}$ behind the centre of the pin and at the edge of the shoulder as the heat source retreats and the material begins to cool and tensile yielding occurs, in (e), the formation of tensile stresses after cooling, and in (f) the final stress state after removal of the tensioning loads. All plots correspond to a heat input representing the welding parameters of $770 \mathrm{rpm}$ and $195 \mathrm{~mm} / \mathrm{min}$ for an AA2024-T6 plate.

tool that generates the residuals stresses is considerably larger than the tool dimensions, so that, fortunately from the point of view of model complexity, one would not expect the residual stresses to be greatly affected by the mechanical action of the tool.

\subsection{The effect of global tensioning}

Examination of the strains and stresses plotted in Figs. 7-9, as a function of the tensioning level, clearly confirms that mechanical tensioning affects both the compressive yielding ahead, and tensile yielding behind, the tool. The imposed tensile stress reduces the amount of compressive yielding that occurs ahead of the weld and the resultant misfit formed. Behind the tool, tensioning encourages increased longitudinal tensile straining of the cooling material in the softened (hot) zone. The tensile misfit thus generated can either decrease the magnitude of the tensile stress (for tensioning levels less than $\sim 40 \%$ ), or introduce significant compressive residual stresses (for tensioning levels greater than $\sim 40 \%$ ). A further observation is that tensioning along the welding direction has far less influence on the other stress components (see Fig. 8).

The effect of tensioning on the compressive stress field and plastic relaxation can be clearly discerned in Figs. 7-9, which shows how the far-field stress reduces the extent of the compressive bow wave ahead of the tool (Fig. 9(a)). Becoming much narrower with increasing tensioning level, the compressive field reduces in width until it lies well within the narrower trailing tensile plastic zone, so that the tensile plastic strains can cancel out, or even overwrite, the compressive plastic misfit with a significant tensile misfit. In Fig. 8(b) and (c) it can be seen that $\sigma_{11}$ becomes less compressive ahead of the tool as the tensioning level is increased, only just becoming compressive near the edge of the tool for the $70 \%$ case. Because of this effect, compressive plastic straining ahead of the tool is much reduced with increased tensioning. At tensioning levels greater than $\sim 40 \%$ there is little to no compressive relaxation of $\sigma_{11}$ ahead of the tool, however the increasing far field tensile strain imposed on the relatively low strength hot material in the thermal field trailing the weld, results in progressively higher levels of tensile relaxation behind 


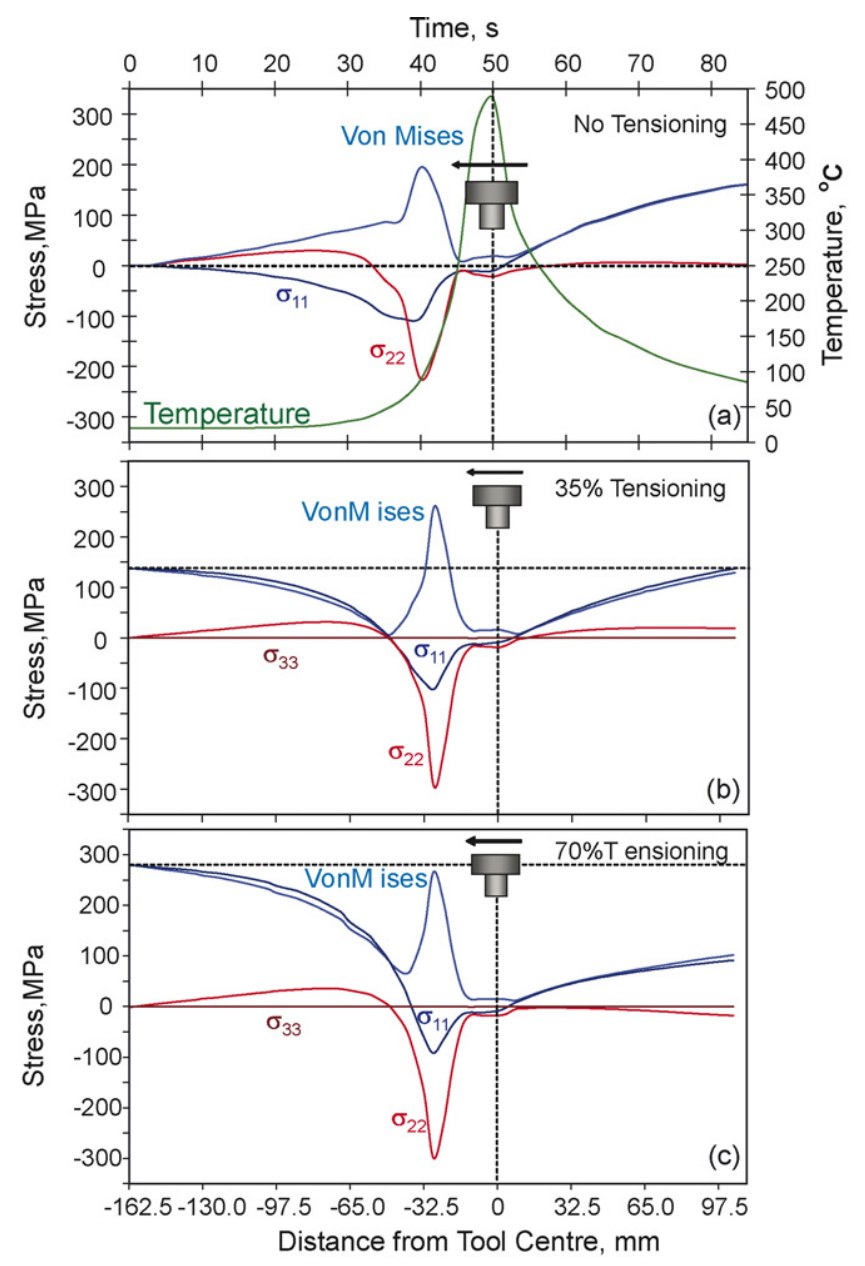

Fig. 8. Development of the longitudinal $\left(\sigma_{11}\right)$, transverse $\left(\sigma_{22}\right)$ and normal $\left(\sigma_{33}\right)$ and Von Mises stresses with distance along the weld centreline predicted from the model, for (a), un-tensioned, (b), 35\% tensioned, and (c), 70\% tensioned, welds in AA2024-T6 3mm plates, using the standard conditions given in Table 1 for Data Set I. In (a) the thermal cycle is shown for comparison. The position and travel direction of the tool is indicated in each figure.

the tool, in a narrow zone close to the weld centre line, where the material is softest (Fig. 7(e)). In the case of 35\% tensioning little tensile straining occurs after the tool has passed such that the net plastic misfit is negligible (Fig. 9(b)). As a result, on removing the tensioning the final residual stresses are approximately zero (Fig. 7(f)). For the $70 \%$ load the plate is over-tensioned due to excessive tensile straining in the wake of the tool (Fig. 9(b)) and on removing the tensioning load the tensile plastic misfit results in a compressive residual stress trough at the centre of the weld (Fig. 7(f)). Except at high tensioning levels, the broader compressive plastic strain field ahead of the tool, compared to the narrow tensile strained region after it, means that a characteristic ' $M$ ' shape arises in the very hot low yield stress region near the weld line.

Taken overall, it can be seen that the mechanical tensioning technique is a very effective approach. It allows the otherwise large longitudinal residual stresses present in welding to be reduced to virtually zero, by choosing the appropriate tensioning level, guided by a suitable model.

\subsection{Sensitivity of mechanical tensioning to the welding conditions}

In FSW it is possible to vary the heat input and line energy by changing the tool rotation and traverse speeds. However, the heat input is normally determined primarily by the tool rotational speed [2]. Here, the extent to which the tensioning level must be adjusted as a function of the processing parameters is investigated by systematically varying the power and traverse speed across a wider process window than can be applied in practice to obtain good welds. The heat input in the model was varied between 435 and $958 \mathrm{~W}$ for a constant traverse speed of $195 \mathrm{~mm} / \mathrm{min}$ (the calibration traverse speed). At $435 \mathrm{~W}$ the nugget zone temperature would be too low $\left(223^{\circ} \mathrm{C}\right)$ to produce a real weld, but this condition was used to provide an extreme case where the strain field around the weld is largely elastic. The traverse speed was varied between 100 and $406 \mathrm{~mm} / \mathrm{min}$, while keeping the power constant at $958 \mathrm{~W}$ (the calibrated power). In practice it is very difficult to decouple the heat input from the traverse speed, as the heat generation is a complex function of the material flow and boundary conditions [28,33-36]. Simulations were then carried out, at different tensioning levels, to determine the effect on the residual stress distribution for these conditions. These results are summarised in Fig. 10, in terms of the predicted peak longitudinal residual stress after relaxation.

In Fig. 10(a) it can be seen that for realistic welding powers (i.e. ignoring the $435 \mathrm{~W}$ curve) and modest tensioning levels, the effect of tensioning is effectively linear in all cases. There is a drift towards higher peak stress levels for higher heat inputs, which is in accordance with experimental observations for the effect of heat input on untensioned samples (Fig. 5) [20]. This is because the different heat input levels mainly expand and contract the thermal field, which largely moves the residual stress peaks in and out, relative to the weld line, rather than greatly affecting the stress level at which the tensile stresses get locked in during cooling behind the tool. It is important to note that, although the maximum stresses are not dramatically affected by reducing the power, the total strain energy stored in the plates will be much reduced as a result of this behaviour. However, if the heat input is reduced to a low level where unrealistic weld temperatures are produced (e.g. $435 \mathrm{~W}$ ), the slope changes dramatically due to the material starting to become substantially harder at the weld centre line. This generally reduces the thermal misfit caused by plastic relaxation, as well as the effectiveness of the tensioning technique. A bigger difference is seen at high tensioning levels where the slope of the curves reduces with decreasing heat input. This is because the more rapid drop in temperature in the tensile zone behind the tool, as the heat input falls, makes it harder to induce as large tensile plastic strains along the weld line, and results in a lower compressive stress level when the tensioning is removed.

Increasing the welding speed reduces the overall line energy, but will also change the shape of the thermal field by compressing the isotherms ahead of the tool and extending the isotherms behind the tool, while narrowing the thermal field. How these factors interact with thermal stress field development, its relaxation and the effect of the far field tensioning stresses has not yet 

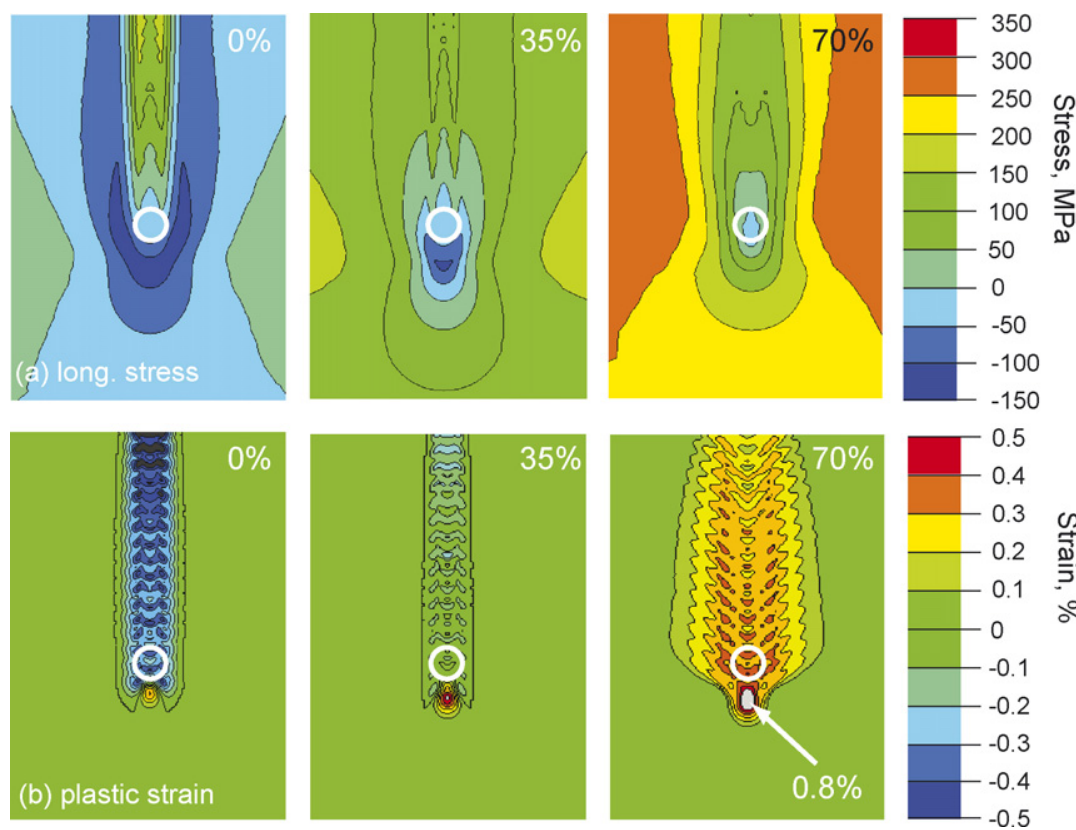

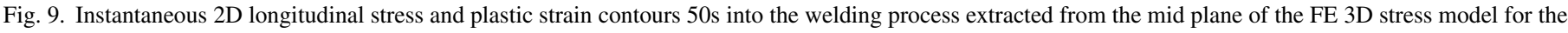

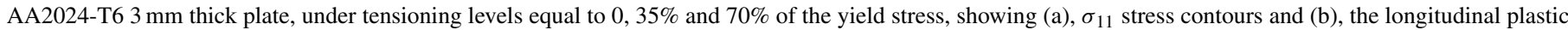

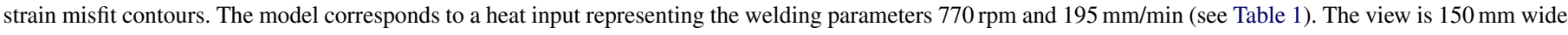
in each case.

been studied in detail, but in comparison to changing the heat input the welding speed appears to have a relatively small effect on the residual stresses and effectiveness of the tensioning level (Fig. 10(b)). However, the influence is again more noticeable at high tensioning levels where compressive residual stresses are developed at the weld line on removal of the tensioning loads, probably as a result in the fall in weld temperature with a constant weld power.

\subsection{Effectiveness of post-weld mechanical tensioning}

Rather than apply tensioning during the welding process, an alternative approach, which can be more convenient in certain situations, is to apply tensioning loads after welding [20]. In Fig. 11(b) the maximum longitudinal residual stress expected for post-weld tensioning, under the welding condition for Data Set II in Table 1, are compared to those obtained previously when tensioning was applied during welding, as a function of tensioning level. Measured values of distortion are included as an additional comparison (Fig. 11(a)). These simulations clearly show that post-weld tensioning, when the whole sample is cold, and the weld zone material has partially recovered and has a higher yield stress than during welding, is much less effective in relaxing the residual stresses than when mechanical tensioning is applied during the welding process. In this case the relative misfit between the near weld region and plate must be removed by tensile straining to a stress level where the softened, thermally affected weld region yields plastically. Because the room temperature yield stress in the softest weld zone (typically the TMAZ/HAZ border [43]) is at least $60 \%$ of the strength of the parent plate (see Fig. 4(b)), very little change is observed in the values of residual stress or distortion until the applied tension exceeds $35-50 \%$ of the yield stress. This is in contrast to tensioning applied during welding, where the far lower elevated temperature yield stress, and interaction with the dynamic stress field around the heat source, results in an observed improvement
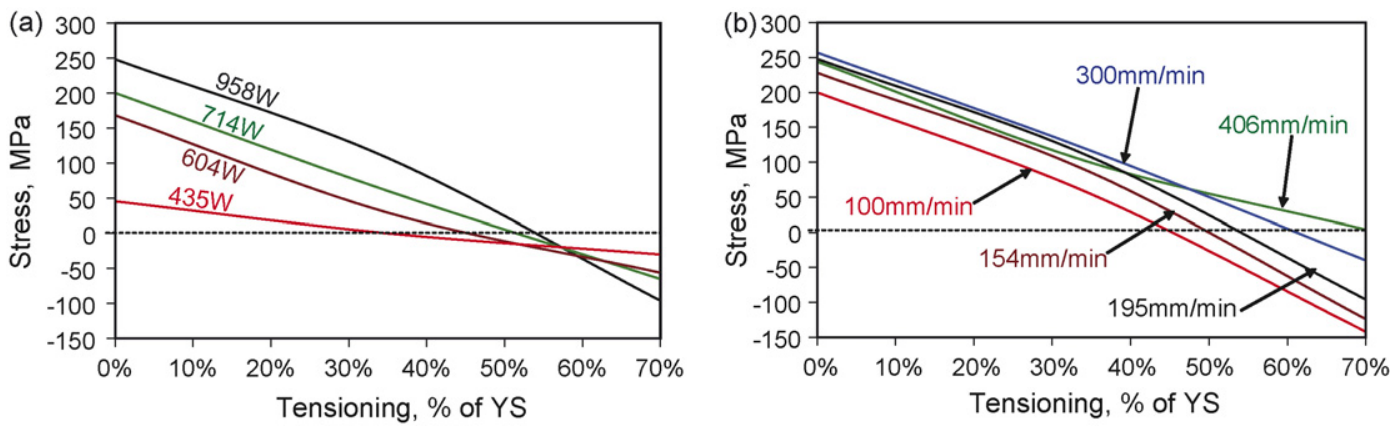

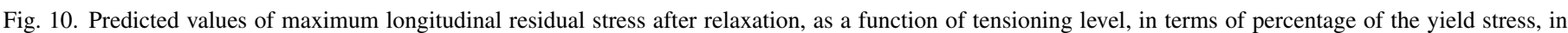

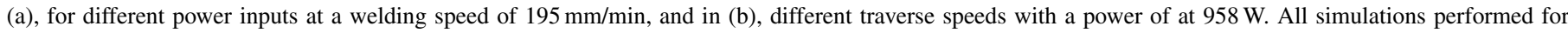
AA2024-T6 $350 \mathrm{~mm} \times 250 \mathrm{~mm} \times 3 \mathrm{~mm}$ plates. 

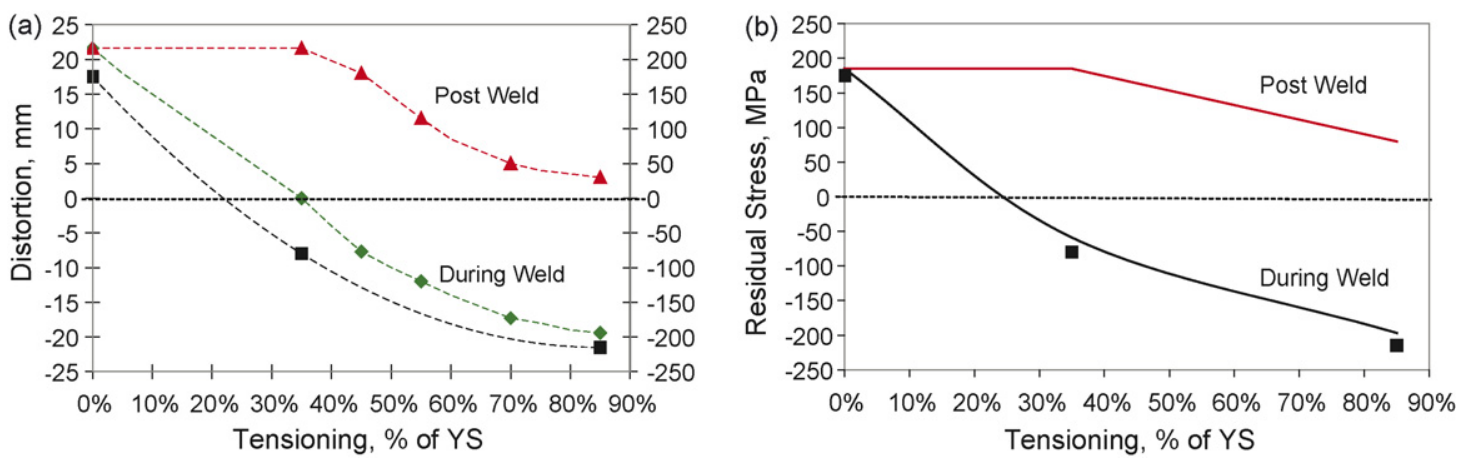

Fig. 11. Comparison of distortion and limited residual stress data taken from [20] with the maximum longitudinal residual stress predicted from the model. In (a), measured longitudinal residual stress (squares) and distortion (diamonds) for tensioning applied during welding, along with distortion data for post-weld tensioning (triangles), and in (b), measured (squares) and predicted values of maximum longitudinal residual stress, as a function of tensioning level, for tensioning during welding compared to the case where tensioning is applied after welding. The figures correspond to AA2024-T3 3 mm plate using the welding parameters specified in Table 1 for Data Set II.

for tensioning levels for as low as $10 \%$ of the room temperature yield stress.

\section{Conclusions}

The principles behind the global mechanical tensioning technique for controlling residual stresses in welding have been investigated using a relatively simple FE model, applied to friction stir welding, based on representing the process purely in terms of a moving heat source. When coupled to a temperature and kinetically dependent material softening model, this approach has been shown to be very successful for obtaining reliable residual stress predictions and for exploring the effectiveness of the tensioning method. Modelling has revealed that in agreement with experimental data the longitudinal peak residual stresses are strongly influenced by the tensioning level. With increased tensioning the weld stresses were seen to fall approximately linearly, reaching zero for tensioning stresses of $\sim 40 \%$ of the material's yield stress. Under larger levels of tensioning the normal longitudinal tensile peak weld residual stresses are replaced by compressive stresses.

Tensioning operates by reducing the compressive bow wave ahead of the traveling heat source and increasing the tensile plastic strain developed in the hot zone trailing the weld. Without tensioning, a large compressive thermally induced misfit strain field ahead of the heat source is formed, which causes compressive plastic straining where the material is hot and thus soft near the tool. On cooling, a tensile stress then develops behind the tool due to the compressive misfit. This tensile stress is partially plastically relaxed except very near to the weld line (where it introduces the ' $\mathrm{M}$ ' profile referred to earlier) due to the rapidly falling temperature and thus increasing load bearing capacity of the material. This results in the tensile longitudinal residual stress state conventionally seen after welding. The model indicates that for low levels of tensioning $(<40 \%)$ a reduction in the compressive plastic strain field ahead of the tool, as the hot material expands, is mainly responsible for reducing the final residual stresses. At higher tensioning loads, little or no compressive misfit develops ahead of the tool. Instead larger levels of tensile plastic straining of the softened hot material after the tool has passed, causes a tensile misfit, or 'over tensioning', once the tensioning forces are removed. This results in the compressive longitudinal stresses seen along the weld line. Taken together, these effects give rise to the observed approximately linear reduction in longitudinal weld stresses with tensioning level and zero residual stresses can be engineered at tensioning levels of $\sim 40-50 \%$, depending on the material and welding conditions. While the main features of the response can be explained predominantly in terms of the longitudinal stresses and misfits, the stress in thin plate is inherently biaxial, with significant yield level stresses in the transverse direction ahead of the tool. The model further indicates that the sensitivity of the resultant peak stresses to varying heat input (rotation speed) and traverse speed is relatively slight. However, a low heat input makes it harder to induce a compressive stress state in the weld at high tensioning levels.

Finally, with regard to post-weld tensioning. The far higher material flow stress within the weld zone at ambient temperatures combined with the missed opportunity for the tensioning stress to interact with the transient stress field created during welding, means that post-weld tensioning is far less effective in engineering the residual stress state than mechanical tensioning applied during welding.

\section{Acknowledgements}

The authors would like to thank A. Wescott, S. Morgan, D. Price of BAE Systems, M. Poad of Airbus UK, and J. Altenkirch, and A. Steuwer for the provision of samples and residual stress diffraction data. This work is supported through the University of Manchester EPSRC Light Alloys Portfolio Partnership (EP/D029201/1) in collaboration with Airbus UK.

\section{References}

[1] W.M. Thomas, E.D. Nicholas, Mater. Des. 18 (1997) 269-273.

[2] M. Peel, A. Steuwer, M. Preuss, P.J. Withers, Acta Mater. 51 (2003) 4791-4801.

[3] P. Staron, M. Kocak, S.W. Williams, A. Wescott, Phys. B: Condens. Matter 350 (2004) E491-E493.

[4] M. Ericsson, R. Sandström, Int. J. Fatigue 25 (2003) 1379-1387. 
[5] K. Masubuchi, Analysis of Welded Structures: Residual Stresses, Distortion and Their Consequences, Pergamon Press, Oxford, 1980.

[6] G. Bussu, P.E. Irving, Int. J. Fatigue 25 (1) (2003) 77-88.

[7] P.S. Pao, S.J. Gill, C.R. Feng, K.K. Sankaran, Scripta Mater. 45 (2001) 605-612.

[8] S.W. Williams, D.A. Price, A. Wescott, C.J.C. Harrison, P. Staron, R. Kocak, Proceedings of the Distortion Control in Welding by Stress Engineering. Welding and Brazing of Aerospace Structures-Modern Applications and Materials for New and In-Service Parts, Conference Associated with the Berlin Air Show, vol. 229, DVS Berichte, May 12-13, 2004, pp. 95-101.

[9] T.W. Greene, A.A. Holzbaur, Weld. J. Res. Suppl. 11 (1946) 171s-185s.

[10] P.A. McGuire, J.J. Groom, Computational Analysis and Experimental Evaluation for Residual Stresses From Induction Heating, EPRI, Battelle Memorial Institute, 1979, Report (RP1394-4).

[11] P. Michaleris, X. Sun, Weld. J. 76 (1997) 451s-457s.

[12] R.M. Dull, J.R. Dydo, J.J. Russell, Proceedings of the 82nd Annual AWS Convention, Cleveland, 2001, pp. 95-96.

[13] P. Dong, J.K. Hong, P. Rogers, Weld. J. 77 (1998) 439-445.

[14] T.E. Barber, F.W. Brust, H.W, Mishler, M.F. Kanninen, Controlling Residual Stresses by Heat Sink Welding, EPRI, 1981, Report NP-2159-LD.

[15] E.M. van der Aa, M.J.M. Hermans, I.M. Richardson, N.M. van der Pers, R. Delhez, Mater. Sci. Forum 524/525 (2006) 479-484.

[16] J. Gabzdyl, M. Cole, S.W. Williams, D. Price, Proceedings of the 20th International Conference on ICALEO 2001: Applications of Lasers \& Electro-Optics, USA, 2001.

[17] Y.P. Yang, P. Dong, X. Tian, Z. Zhang, Proceedings of the 5th International Conference, Trends in Welding Research, 1998. Pine Mountain, pp. 700-705.

[18] Y.P. Yang, P. Dong, J. Zhang, X. Tian, Weld. J. Res. Suppl. 79 (2000) $9 \mathrm{~s}-17 \mathrm{~s}$.

[19] A. Steuwer, M. Peel, T. Buslaps, Mater. Sci. Forum 524/525 (2006) 267-272.

[20] S.W. Williams, D.A. Price, A. Wescott, C.J.C. Harrison, A. Rezai, A. Steuwer, M. Peel, P. Staron, M. Koçak, Sci. Technol. Weld. 12 (2007) 620-633.

[21] J. Altenkirch, A. Steuwer, M. Peel, D.G. Richards, P.J. Withers, Mat. Sci. Eng. A 448 (2008) 16-24.

[22] J.R. Dydo, W. Cheng, Proceedings of the 9th International Conference on Computer Technology in Welding, Detroit, 1999.
[23] Y.J. Chao, X. Qi, W. Tang, J. Manuf. Sci. Eng. 125 (2003) 138-145.

[24] M. Song, R. Kovacevic, Int. J. Mach. Tools Manuf. 43 (2003) 605-615.

[25] P. Ulysse, Int. J. Mach. Tools Manuf. 42 (2002) 1549-1557.

[26] Q. Shi, T. Dickerson, H.R. Shercliff, Proceedings of the 4th International Symposium on FSW (CD ROM), TWI, Utah, USA, 2003.

[27] C.M. Chen, R. Kovacevic, Int. J. Mach. Tools Manuf. 43 (2003) 1319-1326.

[28] P.A. Colegrove, 3 Dimensional Flow and Thermal Modelling of the Friction Stir Welding Process. MSc Dissertation in Department of Mechanical Engineering, University of Adelaide, 2001

[29] R.V. Preston, H.R. Shercliff, P.J. Withers, S. Smith, Acta Mater. 52 (2004) 4973-4983.

[30] R.V. Preston, H.R. Shercliff, P.J. Withers, S. Smith, Sci. Technol. Weld. Joining 8 (2003) 10-18.

[31] S. Benavides, Y. Li, L.E. Murr, D. Brown, J.C. McClure, Scripta Mater. 41 (1999) 809-815.

[32] Y.J. Chao, X. Qi, Proceedings of the 1st International Symposium on FSW, TWI, Thousand Oakes, 1999.

[33] P.A. Colegrove, M. Painter, D. Graham, T. Miller, Proceedings of the 2nd International Symposium on FSW (CD ROM), Gothenburg, Sweden, 1999.

[34] P.A. Colegrove, H.R. Shercliff, J. Mater. Process. Technol. 169 (2005) 320-327.

[35] P.A. Colegrove, H.R. Shercliff, Sci. Technol. Weld. Joining 9 (2004) 349-351.

[36] P.A. Colegrove, H.R. Shercliff, Sci. Technol. Weld. Joining 9 (2004) 352-361.

[37] W. Tang, G. Xi, J.C. McClure, L.E. Murr, J. Mater. Process. Manuf. Sci. 7 (1999) 163-172.

[38] C.J. Harrison, Material Properties Summary. European Union 5th Framework Project (WAFS), BAE Systems, 2004.

[39] J.D. Robson, A. Sullivan, H.R. Shercliff, G. McShane, Proceedings of the 5th International Symposium on Friction Stir Welding, Metz, France, 2004.

[40] O.R. Myhr, Ø. Grong, Acta Metall. 39 (1991) 2693-2702.

[41] P.J. Withers, M. Preuss, A. Steuwer, J.W.L. Pang, J. Appl. Cryst. 40 (2007) 891-904.

[42] M.T. Hutchings, P.J. Withers, T.M. Holden, T. Lorentzen, Introduction to the Characterisation of Residual Stresses by Neutron Diffraction, CRC Press, Taylor \& Francis, London, 2005, 424 p.

[43] R.S. Mishra, Z.Y. Ma, Mater. Sci. Eng: Res. Rep. 50 (2005) 1-78. 